\title{
Utilizing environmental DNA for fish eradication effectiveness monitoring in streams
}

\author{
Gregg Schumer $\mathbb{B} \cdot$ Kristopher Crowley $\cdot$ Erica Maltz $\cdot$ Myfanwy Johnston • \\ Paul Anders $\cdot$ Scott Blankenship
}

Received: 26 September 2018/ Accepted: 9 July 2019/Published online: 17 July 2019

(C) The Author(s) 2019

\begin{abstract}
Introductions of non-native fish have the potential to cause substantial economic and ecological losses. In the western United States, non-native brook trout (Salvelinus fontinalis) are widely established and pose a threat to the persistence of bull trout (Salvelinus confluentus), a native char listed as threatened under the US Endangered Species Act, due to competition and hybridization. With brook trout identified as a factor limiting the recovery of ESA-listed bull trout in the Malheur Watershed of eastern Oregon, managers are pursuing brook trout eradication efforts. Key to the eradication efforts is reliable monitoring to ensure success. Traditional monitoring practices have included mechanical sampling methods such as seining, netting, and electrofishing, all of which are labor intensive and limited in reliability. Environmental
\end{abstract}

Electronic supplementary material The online version of this article (https://doi.org/10.1007/s10530-019-02056-z) contains supplementary material, which is available to authorized users.

G. Schumer $(\varangle) \cdot$ M. Johnston · S. Blankenship Cramer Fish Sciences-Genidaqs, 3300 Industrial Blvd.

Suite 100, West Sacramento, CA 95691, USA

e-mail: greggs@fishsciences.net

K. Crowley · E. Maltz

Natural Resources Department, Burns Paiute Tribe, 100

Pasigo St., Burns, OR 97720, USA

P. Anders

Cramer Fish Sciences, 121 S. Jackson St., Moscow,

ID 83843, USA
DNA (eDNA) is genetic material naturally shed by organisms that can be found in bulk environmental samples without isolating individual organisms. Sampling for eDNA can often be done with less time and expense than traditional methods, making it ideal for effectiveness monitoring following fish eradication efforts. This study placed a single fish in a live-car where the species was not otherwise present and used eDNA sampling to infer the likelihood of detection downstream. Results suggest that a single fish can be detected reliably up to $500 \mathrm{~m}$ downstream when multiple samples are taken. This eDNA sampling method provides managers with the ability to conduct eradication effectiveness monitoring reliably and rapidly and may also be used to detect new fish invasions as well as rare or cryptic species.

Keywords Compliance monitoring - eDNA . Invasive species $\cdot \mathrm{qPCR} \cdot$ Salvelinus fontinalis

\section{Introduction}

Fishes are among the most introduced groups of aquatic animals in the world due to human societal demands for food sources, sport fishing opportunities, ornamental fish trade, and fishery enhancement (Gozlan 2008). The positive revenue contribution of sport fishing in the US has been estimated as 69 billion (\$US) annually, with an associated 5.4 billion (\$US) in 
economic losses due to non-natives (Bjergo et al. 1995). Overall economic benefits are challenging to tabulate, as control and/or eradication costs for pest species are generally not included in economic analyses, let alone the collateral impacts of agriculture or land use restrictions (Pimentel et al. 2005). Nonnative fishes can have complex biological impacts on native species and their ecosystems through competition, hybridization, novel disease exposure or habitat alteration (Gozlan et al. 2010). Notable examples of documented adverse effects from non-native fish invasions are brown trout (Salmo trutta) in New Zealand (McDowall 2003) and the Nile perch (Lates niloticus) introductions into Lake Victoria (Pringle 2005).

Despite potential ecological risks, human-mediated introductions have been common for salmonid species, in particular rainbow trout (Oncorhynchus mykiss), brown trout (S. trutta) and brook trout (Salvelinus fontinalis). Germane to the present study, introduced and invasive brook trout pose a threat to the persistence of bull trout (Salvelinus confluentus), a char native to northwestern North America, in their southern range due to competition (Gunckel 2001), overlapping spawning times, and the ability to produce viable hybrids (DeHaan et al. 2010). Myriad habitat factors have also imperiled bull trout, which is listed at the species level as threatened under the US Endangered Species Act within the Continental US. In portions of its range, the development and implementation of a comprehensive brook trout eradication and control strategy was listed in the 2015 US Fish and Wildlife Bull Trout Recovery Plan as 'an action that must be taken to prevent extinction or prevent the species from declining irreversibly in the foreseeable future' (US Fish and Wildlife Service 2015).

Non-native brook trout exist in high numbers in the Upper Malheur River Watershed, located in Eastern Oregon (Fig. 1), where they are well-documented as detrimental to native trout species (Gunckel 2001). As part of the collaboratively-developed Upper Malheur Watershed Bull Trout Conservation Strategy, the Burns Paiute Tribe is proposing a 10-year effort designed to eradicate brook trout from headwater systems using the piscicide rotenone to benefit bull trout (Burnes Paiute Tribe, Resolution 2018-09). As closed systems, lakes are more amenable to successful application of biocides than rivers (Britton et al. 2009). Upper Lake Creek and its alpine source, High Lake, flow through Tribally-owned land and have been identified as the starting point for brook trout eradication efforts (Fig. 1). With brook trout identified as a limiting factor to the recovery of ESA-listed bull trout in the Malheur Watershed (US Fish and Wildlife Service 2002), the success of an eradication strategy has direct implications for how the Burns Paiute Tribe manages its property and natural resources.

An important aspect of any fish eradication strategy is the determination of treatment phase success at removing all individuals. Methods previously used for this purpose, such as electrofishing and gill nets, are labor-intensive and less sensitive than environmental DNA (eDNA) analysis (Civade et al. 2016; Evans et al. 2017). Determining the presence of a species using traditional methods becomes even less reliable when the target species is rare, as would be the case if survival is minimal after piscicide application. Additionally, these methods are limited in that they cannot confidently determine the absence of fish, even if no fish are captured. While eDNA sampling and detection probabilities are affected by adverse sampling conditions, such as high turbidity and low sample volumes per filter, they can be improved by increasing the number of filter replicates and therefore total volume sampled. Environmental DNA sampling has the potential to be an ideal tool for effectiveness monitoring of fish removals because of the associated ease of collections, and its cost-effectiveness, sensitivity, and high probability of detecting small numbers of remaining fish (Rees et al. 2014; Jane et al. 2015; Civade et al. 2016; Wilcox et al. 2016). Additionally, unlike mechanical sampling methods, there is no potential for avoidance behaviors because eDNA sampling involves indirect observation that does not require capture or handling of any individuals. The successful use of eDNA as a tool for species detection has been demonstrated in freshwater environments (Teletchea 2009; Thomsen et al. 2011; Jerde et al. 2011; Laramie et al. 2015; Civade et al. 2016).

The present study documents the establishment of a species-specific quantitative polymerase chain reaction (qPCR) assay for brook trout along with controlled field sampling experiments to determine the detection parameters of a single individual fish using eDNA methods. The study was designed to determine the minimum threshold for the detection of brook trout eDNA to optimize effectiveness monitoring of brook trout removal from purposed eradication efforts. The 


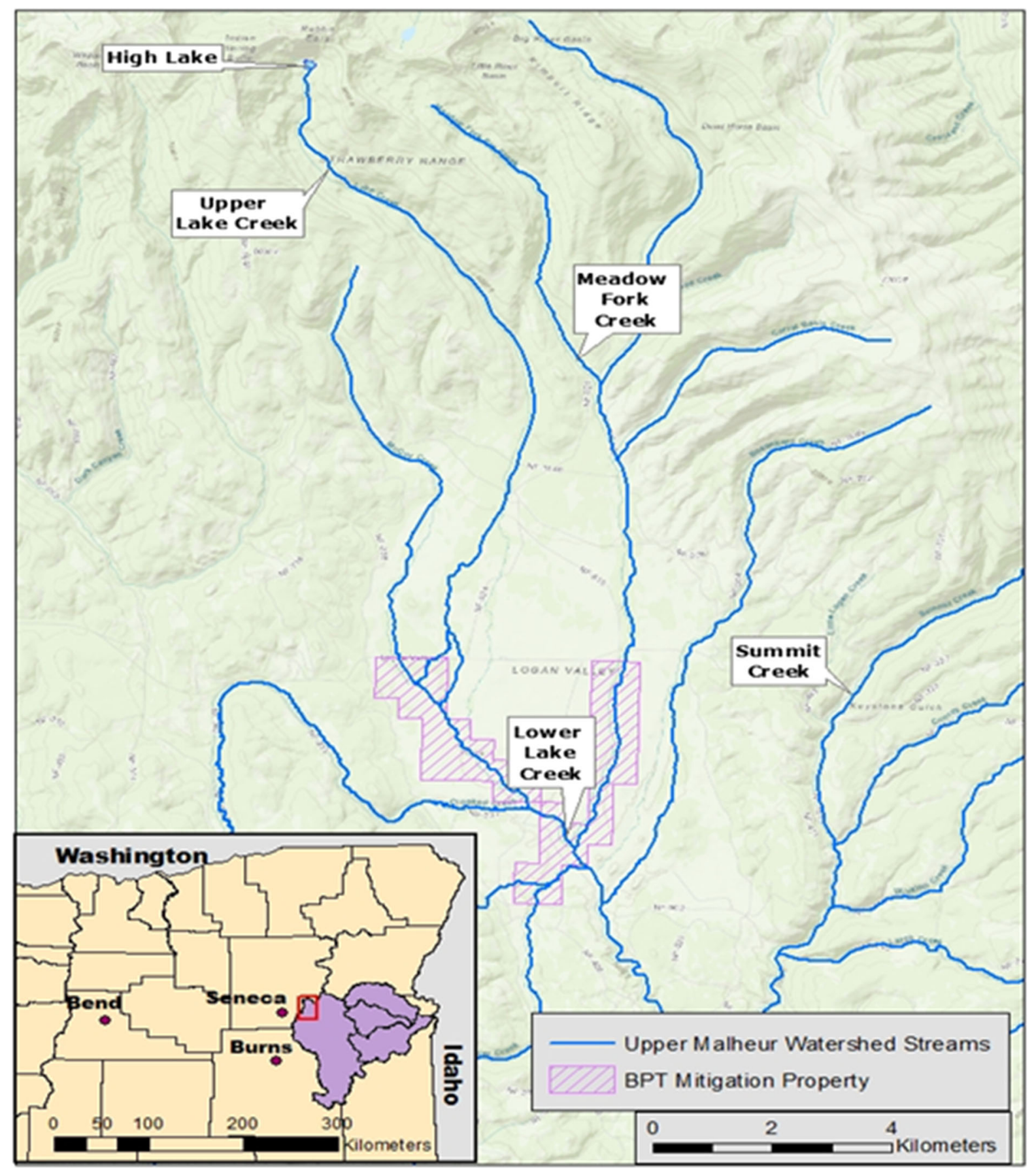

Fig. 1 Study area in the Upper Malheur River Watershed with study locations labeled

sampling recommendations developed by this project will refine the technology's application and enhance transferability and use by providing a consistent and statistically sound sampling procedure. Credible detection processes will streamline land management decisions and provide cost effective means of conclusively determining the presence or absence of fish on a species-specific basis. 


\section{Materials and methods}

DNA barcoding and qPCR assay design

In 2011, 29 right pelvic fins of brook trout were collected and placed loosely in an envelope and allowed to dry before flattening (Oregon Scientific Taking Permit \#16297, Supplemental Table 2). Filter paper was not available to dry out the fin clips, so fins were placed loosely on paper partially within an envelope to air dry prior to closing. Using Qiagen DNeasy blood and tissue kit (Qiagen Inc.) total DNA, genomic and mitochondrial, was extracted from six fin clips following manufacturers guidelines.

To design a species-specific $5^{\prime}$ exonuclease assay, a 485 bp segment of the mitochondrial cytochrome $b$ gene $(C y t b)$ was sequenced for six brook trout using conserved animal primers, H15149 and L14724 (Kocher et al. 1989; Irwin et al. 1991). Resulting Cytb sequences were aligned using Sequencher software version 4.8 (Gene Codes). Using the $485 \mathrm{bp}$ fragment from the brook trout $C y t b$ region as a template, a BLAST search was conducted against the NCBI nucleotide database to search for a sequence of conserved DNA specific to brook trout while having the greatest amount of heterogeneity compared to closely related co-existing species. From this conserved region of the brook Cytb gene, a forward primer, reverse primer, and a species-specific probe were designed using Primer Express ${ }^{\circledR}$ Oligo Design software (Applied Biosystems) to perform a $5^{\prime}$ exonuclease (TaqMan $^{\mathrm{TM}}$ MGB Probe) assay (Table 1). An additional BLAST search was conducted on the assay amplicon to ensure in silico specificity.

qPCR assay validation

The assay was optimized following Thermo Fisher Life Technologies protocol for the optimization of primers and probe. For samples used to validate the species-specific assay, PCR was performed in a $10 \mu \mathrm{L}$ total volume containing: $4 \mu \mathrm{L}$ DNA template, $2 \mathrm{X}$ TaqMan ${ }^{\circledR}$ Master Mix (Thermo Fisher Life Technologies) with optimized concentrations of both forward and reverse primers and for the probe. Thermal cycling occurred with Bio-Rad's CFX 96 real-time detector under the following conditions: initial enzyme activation of $10 \mathrm{~min}$ at $95{ }^{\circ} \mathrm{C}, 40$ cycles of 15 s denaturation at $95{ }^{\circ} \mathrm{C}, 1 \mathrm{~min}$ annealing/extension at $60{ }^{\circ} \mathrm{C}$. The number of PCR cycles required for reaction fluorescence $(\mathrm{C}(\mathrm{q})$ ) values were quantified using CFX Manager ${ }^{\mathrm{TM}}$ (version 3.1; Bio-Rad). The assay was also validated in vitro for specificity by testing for cross reactivity with a panel of common fish species including: Salvelinus confluentus (bull trout), Oncorhynchus mykiss (rainbow trout), Alosa sapidissima (American Shad), Percina macrolepida (bigscale logperch), Pomoxis nigromaculatus (black crappie), Lepomis macrochirus (bluegill), Cyprinus carpio (common carp), Ictalurus punctatus (channel catfish), Micropterus salmoides (largemouth bass), Spirinchus thaleichthys (longfin smelt), Menidia beryllina (Mississippi silverside), Gambusia affinis (mosquito fish), Clupea pallasii (Pacific herring), Cottus asper (prickly sculpin), Lepomis gibbosus (pumpkinseed), Catostomus occidentalis (Sacramento sucker), Tridentiger bifasciatus (shimofuri goby), Pogonichthys macrolepidotus (Sacramento splittail), Morone saxatilis (striped bass), Dorosoma petenense (threadfin shad), Hypomesus nipponensis (wakasagi smelt), Ameiurus catus (white catfish), Pomoxis annularis (white crappie), and Acanthogobius flavimanus (yellowfin goby). Eight no-template controls were included per plate and the threshold was set above background fluorescence. No contamination was observed in the no-template control samples. A cross amplification panel was tested in triplicate. Sensitivity of the assay was determined by tenfold serial dilution of a positive control derived from brook trout fin clips

Table $1 C y t b$ assay primer and probe sequences used for Brook Trout eDNA surveys

\begin{tabular}{lllc}
\hline Species & Oligo & Sequence 5'-3' & Reporter \\
\hline Salvelinus fontinalis & BRT $C y t b$-F & TGGCCAACCTCCGAAAAAC & \\
Salvelinus fontinalis & BRT $C y t b$-R & AGGTCGACTAGTGCGTCATTAGC & 6 FAM \\
Salvelinus fontinalis & BRT $C y t b$ Probe & CCCACTCCTAAAAAT & MGB \\
\hline
\end{tabular}


with a concentration ranging from 20 to $0.00002 \mathrm{ng} /$ $\mu \mathrm{L}$. A brook trout DNA standard curve was constructed to determine the slope (qPCR efficiency), Y-intercept, and $\mathrm{R}^{2}$ values.

eDNA field sampling and sample analysis

\section{Transect associated with electrofishing survey}

Approximately $10 \mathrm{~km}$ of Lake Creek up to and including High Lake was surveyed by Burns Paiute Tribal staff at 84 sites in the summer and fall of 2014 for the presence of bull trout and brook trout. Thirty sites were randomly chosen from the 84-site regime to collect eDNA (water) samples, with all sites surveyed for brook trout using standard visual survey methods. The intent of this sampling was to corroborate brook trout eDNA detections using a designed brook trout qPCR assay with electrofishing confirmation of brook trout presence. During the summer sampling event, eDNA (water) samples were obtained from 18 (of the proscribed 30) sites in Lake Creek and nine eDNA (water) samples were obtained from High Lake (Table 2). During the fall sampling event, eDNA samples were taken from the 30 prescribed sites and nine eDNA samples were taken from High Lake (Table 2).

Environmental DNA samples were obtained from field sites using water filtration procedures following Bergman et al. (2016) and Blankenship and Schumer (2017). Water was pumped from the stream using a battery operated peristaltic pump, with organic material sequestered in a Millipore Sterivex ${ }^{\mathrm{TM}}$ Filter Column (MilliporeSigma). Each eDNA sample was collected using sterile single-use materials and filters were kept on ice while in the field. Filters were frozen prior to shipping, and all filters were shipped overnight on blue ice to Cramer Fish Sciences in California for processing and analysis.

\section{Field experiments: volume and distance sampling from known source}

Field tests were conducted to examine relationships between filtered volume, number of replicate samples, distance from source, and the strength of eDNA detection. Due to the ubiquitous presence of brook trout in the Upper Malheur Watershed, rainbow trout and smallmouth bass were used as proxies for experimental distance tests (Supplemental Table 3). Previously validated species-specific qPCR assays were used for rainbow trout and smallmouth bass (Brandl et al. 2015). Cages were used to hold experimental fish at fixed stream locations and eDNA samples were taken 16-24 h after installation of a single test fish subject at prescribed distances downstream of cage location (100, 250, 500 and $1000 \mathrm{~m}$ ). Cages were installed at sites within a system where proxy fish species were known to be absent. Background or negative control samples were collected within test sites to ensure that neither naturally introduced nor exogenous DNA from either surrogate species was present before or during the experiment.

Field sampling events occurred two or three times a year during different flows and temperatures from 2015 to 2017 (Supplemental Table 4). Sampling events yielded filtered water samples of varying volumes, representing multiple distances and numbers of replicates (Table 2). Flow, temperature, and turbidity were measured in situ according to modified Oregon Department of Environmental Quality Protocols (DEQ). Rosgen classifications for each sampled reach were used to facilitate information transferability and to assist in data interpretation, as these were

Table 2 Summary of events, filtered volumes, and distances from eDNA sources sampled across years

\begin{tabular}{llllr}
\hline Years & Sampling event & Volumes sampled in L (replicate samples per volume) & Distances sampled (m) & Total samples \\
\hline 2015 & 1 & $2.0(2)$ & $0,100,250,500,1000$ & 10 \\
2016 & 1 & $1.0(2), 2.0(1), 4.0(1), 8.0(1)$ & $250,500,1000$ & 5 \\
2016 & 2 & $2.0(1)$ & 250 & 1 \\
2017 & 1 & $0.5(1), 1.0(1), 1.5(1), 2.0(1), 2.5(2), 3.0(2), 3.5(2), 4.0(2)$ & 500 & 12 \\
2017 & 2 & $0.5(1), 1.0(9), 1.5(1), 2.0(1), 2.5(1), 3.0(1), 3.5(1), 4.0(1)$ & 500 & 16 \\
2017 & 3 & $0.5(1), 1.0(2), 1.5(2), 2.0(2), 2.5(2)$ & 500 & 9 \\
\hline
\end{tabular}


readily available for proposed reaches and are a widely utilized stream habitat classification system (Rosgen 1994).

Experimental stream reaches were selected according to a perceived carrying ability of streams based on hydrologic settings including gradient, flow, and temperature in order to obtain a sampling distance that can be applied watershed-wide. Three river sites were selected where smallmouth bass were absent: Meadow Fork of Big Creek (high gradient), Summit Creek (moderate gradient), and Lower Lake Creek (low gradient). For the 2016 experiments, smallmouth bass test subjects were killed prior to installation into cages to avoid accidental release. Permitting restrictions required that any smallmouth bass used as part of this study must be dead prior to use in the field. While evidence suggests the probability of detecting eDNA of live fish differs from that of dead fish (Kamorof and Goldberg 2018), we did not calculate the difference in probability as part of this study. All 2017 sampling events occurred in Lake Creek above Lake Creek Falls. Live rainbow trout were the experimental subjects installed in cages, as rainbow trout are not present upstream from Lake Creek Falls.

\section{Laboratory analysis}

DNA from all samples and controls were extracted using PowerWater Sterivex ${ }^{\mathrm{TM}}$ DNA Isolation Kit (Qiagen, Inc.) following the manufacturer's recommended guidelines. A DNA extraction negative control was processed in parallel to ensure sample integrity throughout the extraction procedure. The DNA extraction control consisted of Sterivex ${ }^{\mathrm{TM}}$ filtered ultrapure water only. DNA extraction controls were processed using the same equipment used to extract DNA from all samples. Each sample and all controls were analyzed in triplicate for the presence of the target species $C y t b$ mitochondrial gene using species-specific brook trout qPCR primer and probe set and laboratory methods described in Bergman et al. (2016). Each $10 \mu \mathrm{L}$ qPCR reaction was conducted as described previously. Thermocycling was performed using a Bio-Rad CFX 96 Real time System (Bio-Rad Laboratories, Inc.) with the following profile: $10 \mathrm{~min}$ at $95{ }^{\circ} \mathrm{C}, 40$ cycles of $15 \mathrm{~s}$ denaturation at $95^{\circ} \mathrm{C}$ and 1 min extension at $60{ }^{\circ} \mathrm{C}$. Field collection controls (i.e., blanks) and a positive DNA template were also used. Positive control reactions consisting of target species genomic DNA template were tested in parallel to ensure consistent PCR performance. All PCR master mixes were made inside a UV-sterilized PCR enclosed workstation. The DNA template was added to the master mix outside of the UV PCR workstation on a dedicated PCR set up workbench. All PCR reactions were conducted on instruments located outside of the main lab in a separate portion of the building. Results of the qPCR reactions were analyzed using BioRad CFX manager v3.1 (Bio-Rad Laboratories, Inc.), with the magnitude of the qPCR signal ("detection strength") reported as the number of quantification cycles $(\mathrm{C}(\mathrm{q}))$. $\mathrm{C}(\mathrm{q})$ is defined as the number of PCR cycles required for reaction fluorescence to exceed background fluorescence. The results of the qPCR reactions were analyzed using BioRad CFX manager v3.1 (Bio-Rad Laboratories, Inc.). Target species DNA was considered to have been detected in a sample if any of three replicates had $\mathrm{C}(\mathrm{q})<40$.

\section{Statistical analysis}

The goal was to determine a sampling protocol for reliably obtaining positive detection of the target species, given its known presence and location. We initially considered sampling location (a proxy for stream gradient), distance from source, filtered volume, and number of replicate samples as primary predictors of the strength and probability of detection. During sampling events in 2016, poor water quality conditions resulted in the combination of multiple Sterivex filters into the same eDNA sample in order to obtain the target filtered volume of water. It was unclear how (or if) this combination process affected the probability of eDNA detection in an individual sample, and how (or if) this was confounded by distance and sampling site. To reduce bias associated with this uncertainty, these multi-filter samples were removed from the data presented in Fig. 2 and Table 2, which summarizes the remaining 53 samples collected from 2015 through 2017. Because this left an uneven distribution of replicate samples across distances and gradients, distance from source and stream gradient were held constant for statistical modeling. For modeling, only samples taken at $500 \mathrm{~m}$ using a single filter per sample from Lake Creek were used. This included 37 samples from 2017, and two samples 
Fig. 2 Detection likelihood range based on the $95 \%$ credible interval for up to five filtered volume replicates; intervals calculated based on a baseline average detection probability of 0.84 , as observed in the model dataset

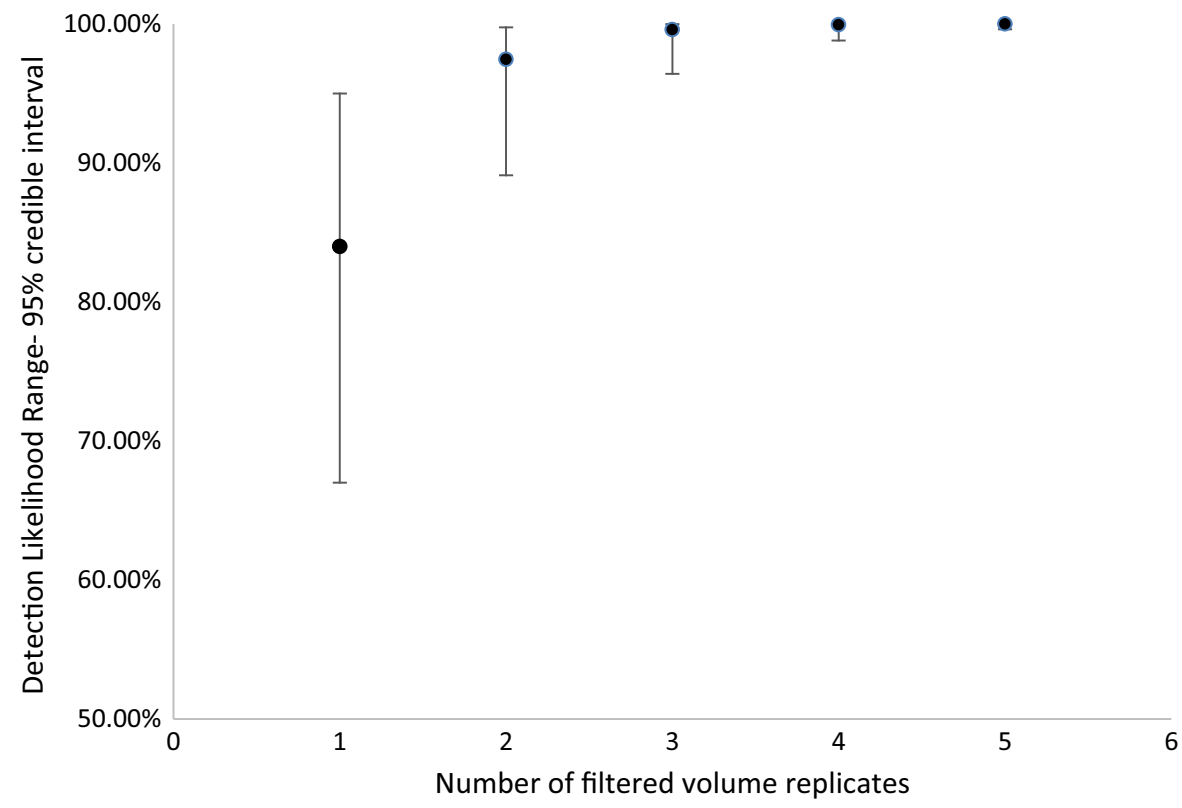

from 2015, for a total of 39 samples in the model dataset.

We chose a Bayesian statistical approach because it allowed us to model detection strength (a continuous variable with an upper bound, preferable to modeling detection as a binary variable) and simultaneously examine whether high-volume samples or high-replicate samples resulted in more positive (binary) detections than low-volume or low-replicate samples. The employed Bayesian framework made this distinction possible through the derivation of a distribution of binary detection probabilities across volumes and number of replicates from the posterior probability distribution of modeled detection strength. The multivariable linear model was written in the Stan programming language and fit using the rstan package (Version 2.17.3) in the statistical computing software $\mathrm{R}$ (Version 3.5.1). Model fit diagnostics included posterior predictive checks, inspection of the potential scale reduction statistic $(\hat{R})$ and effective sample size $\left(n_{\text {eff }}\right)$, and verification that Markov Chain Monte Carlo chains were well-mixed and stationary. Model code is available from www.github.com/fishsciences/ BPT_eDNA.

Equally important to estimating the probability of a positive detection is estimating that of a false negative detection (i.e., failure to detect eDNA when the target species is in fact present). We estimated a detection rate from the observed frequencies of detection across volumes and number of samples and extrapolated that linearly across a potential sampling regime in order to guide future sampling efforts.

\section{Results}

qPCR assay validation

Primer and probe optimization for the brook trout assay determined that an initial concentration of $900 \mathrm{nM}$ for both the forward and reverse primers and $3 \mu \mathrm{M}$ for the probe to be the optimal assay concentrations. Manufacturer recommended qPCR cycle conditions were retained and used for all analyses. All templates derived from known brook trout fin clips were detected with the brook trout species qPCR assay developed for a mitochondria cytochrome b gene locus (Table 1). No contamination was observed in the no-template samples. In-silico specificity BLAST results showed that the brook trout $C y t b$ assay had significant sequence similarity with closely related coexisting species. The in vitro specificity test confirmed in silico results and showed no cross reactivity of the brook trout assay when other common fish species were used as templates. The brook trout assay reliably detected brook trout DNA at a concentration of $0.0002 \mathrm{ng} / \mu \mathrm{L}$ with and average 
C(q) of 35.71 for all five replicates. The standard curve for brook trout produced the slope of -3.327 suggesting a qPCR efficiency of $99.79 \%$. A Y-intercept of 38.32 indicated that the assay was sensitive and did not require amplification beyond 40 cycles to detect target sequences. An $\mathrm{R}^{2}$ of 0.9967 revealed a high correlation between the $\mathrm{C}(\mathrm{q})$ and the concentration of template.

\section{eDNA field samples}

\section{Transect associated with electrofishing survey}

Nineteen eDNA samples were taken from Lake Creek during the summer sampling event, where a duplicate collection was made at site 1 (Supplemental Table 1). Of the nine eDNA samples obtained from High Lake, only eight were analyzed, as the filter corresponding to site 2B was broken. All eDNA samples collected during the summer event tested positive for brook trout DNA (Supplemental Table 1). Twenty-nine eDNA samples collected in the fall from Lake Creek (Site 1 filter broken), as well as the nine High Lake eDNA samples, tested positive for brook trout DNA (Supplemental Table 1). These were the expected results as brook trout were observed at all sites, ranging in density from 0.20 to 1.1 brook trout per meter (Supplemental Table 1). There was a poor correlation between estimated brook trout density and brook trout eDNA concentration within water samples, suggesting no apparent relationship between the measures (data not shown).

\section{eDNA detection across samples}

With the exception of the $8.0 \mathrm{~L}$ single-filter sample collected at $1000 \mathrm{~m}$ from point source, all water filtration volumes had positive detections of target species DNA in at least one eDNA template technical replicate, with several volumes having DNA detections within all technical replicates (100\% detection of eDNA; Fig. 3). On average, target species DNA was detected $62 \%$ of the time across all sampled volumes and distances. The observed frequency of positive and negative detection across volumes is visualized in Fig. 4.
Modeling results

Neither volume, number of samples, nor their interactions were reliable predictors of the strength or probability of detection (Table 3). When the modeled detection strength was used to generate a distribution of binary detection values across different volumes and number of replicates per sampled volume there were no discernable differences in likelihood of positive or negative detection between modeled volumes or number of replicates per volume, regardless of average $\mathrm{C}(\mathrm{q})$ value (average detection strength of three technical replicates). The probability of detecting target species DNA in any single filter was estimated to be 0.84 (0.67-0.95 95\% CI; Table 3). Average $\mathrm{C}(\mathrm{q})$ values of the samples used in the model dataset is plotted by volume in Fig. 4.

\section{Discussion}

This project demonstrated that genetic material naturally shed by fish into the environment can be reliably collected in eDNA (water) samples without directly interrogating individual organisms. While many methodological uncertainties have been recently overcome and the use of eDNA technology has expanded tremendously in the last 5 years as a monitoring tool (Rees et al. 2014; Roussel et al. 2015; Hänfling et al. 2016; Deiner et al. 2016), it was previously unclear what the maximum downstream distance might be for reliable detection of brook trout in the Upper Malheur Watershed. This approach and the resulting information can be applied to sampling designs that aim to minimize monitoring costs and maximize detection probability under a range of eradication scenarios.

Our model suggested that given ambient conditions in the Malheur Watershed, when the target species was present within $500 \mathrm{~m}$, the probability of detecting target species DNA in any single filtered volume was approximately 0.84 (0.67-0.95 95\% credible interval; Table 3). This detection distance was greater than previous observations for brook trout (Jane et al. 2015; Wilcox et al. 2016) but lower than that of Civade et al. (2016) who looked at a diverse fish assemblage. For comparison, Jane et al. (2015) detected fish at up to $300 \mathrm{~m}$, and Wilcox et al. (2016) estimated a 0.18 probability of detection per sample per fish per kilometer stream, also using brook trout. Both these 
Fig. 3 Average C(q) (cycle quantification, a measure of detection strength) across volumes in the model dataset. Negative detections (Avg C(q) $\geq 40$ ) are grouped on the $x$-axis so that the number of negativedetection samples can be compared visually across volumes. Volume was not a reliable predictor of binary detection probability in this dataset, likely because of few negative samples across volumes

Fig. 4 Observed proportions of positive and negative detections for all volumes, distances and years
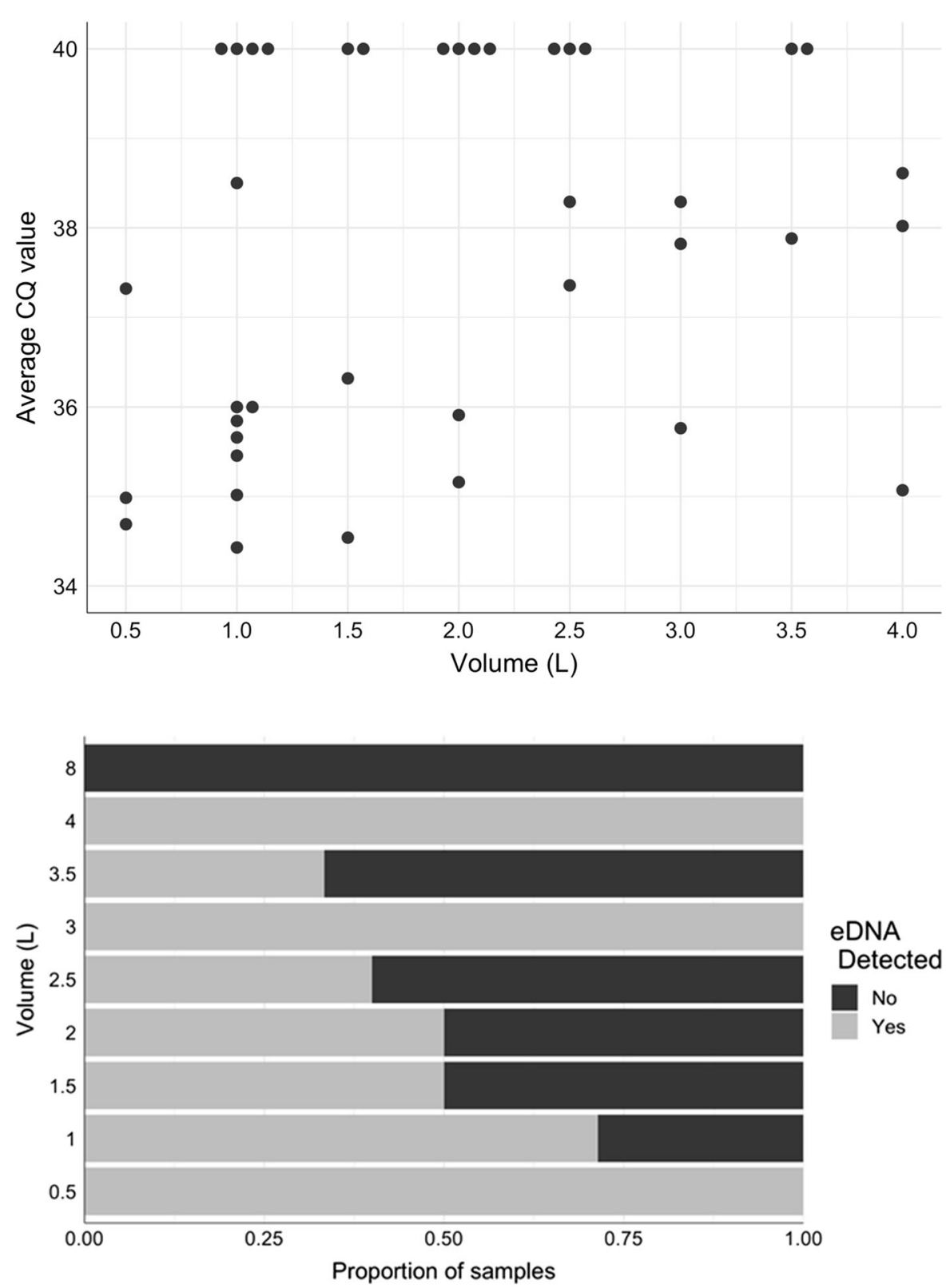

estimates were considerably lower than the 0.84 probability of detection per sample per fish at $500 \mathrm{~m}$ in our study. However, Wilcox et al. (2016) also reported very high detection probabilities for brook trout when sampling at population-level densities (e.g. probability of detection $>0.99$ at densities of $\geq 3$ fish per $100 \mathrm{~m}$ ). Such results further support the effectiveness of using waterborne eDNA sampling to characterize presence or absence of important target species.
In practice, when an environment is associated with $84 \%$ detection probability for a single fish, as seen in this study, collecting two samples theoretically provides an approximate $97 \%$ probability of detection, given that a fish is actually present. Of course, there is stochasticity around individual observations, with precision being of practical importance under any eradication scenario. The eDNA samples used in our model were taken from a fixed distance in a single high-gradient stream environment, and although 
Table 3 Model estimates and credible intervals of each parameter's effect on C(q) value, where a higher C(q) is associated with weaker detection strength, and a $\mathrm{C}(\mathrm{q}) \geq 40$ represents non-detection

\begin{tabular}{lcccc}
\hline Model parameter & Mean & SE & Lower 95\% credible interval & Upper 95\% credible interval \\
\hline Intercept & 36.15 & 0.06 & 33.12 & 39.15 \\
Volume (deciliters) & -0.04 & 0.01 & -0.22 & 0.13 \\
Number of samples & -0.27 & 0.02 & -0.79 & 0.27 \\
Volume $\times$ number of samples & 0.04 & 0.01 & -0.01 & 0.09 \\
Probability of detection & 0.84 & 0.07 & 0.67 & 0.95 \\
\hline
\end{tabular}

Estimates are presented on the outcome scale (i.e., quantification cycles), except for the estimate for mean probability of detection, which is presented on the probability scale. Credible intervals were calculated using the quantile method

samples spanned different seasonal hydrological conditions, in situations where high levels of confidence are desired (e.g. 99.9\%), up to five replicate samples may be required (Fig. 2).

In theory, high-volume samples should have higher probabilities of positive detection relative to lowvolume samples taken at the same distance from the source because the strength of detection is a function of the amount of eDNA captured on the filter. However, when the modeled detection strength was used to generate a distribution of binary detection values across different volumes and number of replicates per sampled volume, all volumes and numbers of replicates generated more positive than negative detections. This indicated that we did not record enough instances of negative detections across volumes and/or number of samples to be able to reliably estimate covariate effects on positive or negative detection; most samples in the model dataset were positive for eDNA. While the high detection rate of target species eDNA renders a conclusion regarding the effect(s) of sample replication and filtration volume on detection ambiguous for the Upper Malheur River Basin, in practice, these results suggest that moderate sampling frequency (e.g. 3-5 samples at a fixed volume and 3 technical replicates per sample) is adequate to detect a single fish at $500 \mathrm{~m}$ with high probability (Table 3). Although we did not model distance from source explicitly, fixed volume $(2.0 \mathrm{~L})$ samples across varying distances $(0-1000 \mathrm{~m})$ reveled a decline in rate of detection with increasing distance, as would be expected.

The Burns Paiute Tribe has a goal of eradicating invasive non-native brook trout from the Upper Malheur River Watershed. An integral part of meeting this goal is the development of cost effective means to monitor eradication success. To increase the probability of success, the Burns Paiute Tribe endeavored to develop sampling procedures specific to local stream conditions to detect species presence post-removal and as a means for early detection of new invasions. The research reported here is a part of the framework for monitoring species distribution using eDNA. By critically evaluating effective eDNA sampling procedures, the Burns Paiute Tribe seeks to maximize the potential of this technology.

Using piscicides to control unwanted or invasive fish can be a desirable option due to its ability to quickly achieve eradication. Although piscicide application is a tool that has been effective in streams, lakes, and ponds throughout the western US for decades, methods for determining success immediately following treatment have remained unreliable and often haphazard. Results presented here suggest that duplicate or triplicate water samples of $1.0 \mathrm{~L}$ filtered at $0.5 \mathrm{~km}$ intervals will detect the presence of a single fish across a variety of stream conditions with high probability. Furthermore, it is feasible for each proposed treatment area in the eradication strategy to be comprehensively sampled using established eDNA procedures in a single day.

The adopted procedure reported here was developed in tributaries to the Upper Malheur River in eastern Oregon. Experiments were strategically repeated during each of three consecutive years to incorporate a broad range of stream conditions resulting from variability in seasonal and annual flow patterns. Since eDNA was detectable across stream conditions during this experiment, we conclude that this procedure will be applicable to streams outside 
our project area, although site-specific detectability may differ. In Lake Creek, up to $4.0 \mathrm{~L}$ of water could pass through a single filter without clogging. This resulted in capturing a large amount of organic material in the filter and may have overloaded the DNA extraction affinity column, thereby reducing the ability of the product to isolate purified DNA (reduced yield). This is consistent with the manufacturers guidelines recommending that a maximum of $2.0 \mathrm{~L}$ should be filtered through the Sterivex ${ }^{\mathrm{TM}} 0.45 \mu \mathrm{m}$ filter. Streams with higher turbidity may be particularly problematic due to the design specifications of the filters used. If suspended sediment or biological turbidity (e.g. algal density) in a stream is high, filters may become clogged before a $1.0 \mathrm{~L}$ sample volume is obtained. In this case, we recommend prioritizing replicates over volume; that is, collecting 4-6 lowvolume samples $(50-500 \mathrm{~mL})$ per site.

Results of this study represent the minimum detection likelihood for a single fish within $500 \mathrm{~m}$. In a real-world scenario, probability of detection may be substantially higher when using this protocol. In our experiments, a single fish was placed at the maximum distance away from the sampling point in a stream reach that was otherwise clean of the species. This is unlikely to be the case under most circumstances in which sampling would occur. Further, the test fish was only in the stream for 16-24 $\mathrm{h}$ prior to sampling. Shedding of eDNA is a continual process throughout the life of fish. Therefore, only sampling soon after a fish is placed in the water may underestimate detectability in a natural setting where fish are in the water over a longer term. Additionally, eDNA is more readily available in the water during certain times of the year such as spawning. Thus, sampling efforts should be focused during these times to increase the probability of detecting target species DNA when feasible.

Specific to piscicide application, post-treatment, large quantities of fish carcasses will remain in the water, shedding large quantities of DNA into the environment as decay occurs. Over time, the eDNA would be flushed out of the system and/or degrade to the point that it is no longer detectable in the water. At this time, managers would be able to systematically sample the water body for DNA at established volumes and intervals to determine treatment success. However, further investigation is needed to determine the rate at which dead fish would decay beyond the point of detectability following piscicide application.

In conclusion, this study provided conclusive empirical proof-of-concept results for a protocol to successfully use eDNA to detect a target species of fish in running water, provide an estimate of the sensitivity of this detection, and assess the relative importance of the parameter sample volume and size, and the number of samples. Based on results of this study, the use of eDNA analysis that includes qPCR and a speciesspecific probe appears well-suited for determining presence/absence of brook trout in running water. The procedure provides a low-cost, rigorous, and logistically feasible protocol for the use of eDNA in remote locations to help remedy key data gaps pertaining to current species range. This approach and the resulting information can be used to enhance effectiveness monitoring of fish eradication efforts.

Acknowledgements Funding for this Project was provided in part by the Natural Resources Conservation Service's Oregon Conservation Innovation Grant program. This program is for stimulating development and adoption of innovative conservation approaches and technologies on agricultural lands in Oregon. The authors would like to thank Larry Dominguez for all of the work put into getting this project realized. Larry had the vision to realize that eDNA methodology was a worthy pursuit in 2010. This all started with Larry and we all thank you very much.

Open Access This article is distributed under the terms of the Creative Commons Attribution 4.0 International License (http:// creativecommons.org/licenses/by/4.0/), which permits unrestricted use, distribution, and reproduction in any medium, provided you give appropriate credit to the original author(s) and the source, provide a link to the Creative Commons license, and indicate if changes were made.

\section{References}

Bergman PS, Schumer G, Blankenship S, Campbell E (2016) Detection of adult green sturgeon using environmental DNA analysis. PLoS ONE 11:e0153500. https://doi.org/ 10.1371/journal.pone. 0153500

Bjergo C, Boydstun C, Crosby M et al (1995) Non-native aquatic species in the United States and coastal water. Our Living Resour Rep Nation Distrib Abundance Health US Plants Anim Ecosyst US Dep Inter Natl Biol Serv Wash DC $428-430$

Blankenship SM, Schumer G (2017) Field collection procedure for aquatic environmental DNA sample collection and analysis. Cramer Fish Sciences/Genidaqs, West Sacramento 
Brandl S, Schumer G, Schreier BM et al (2015) Ten real-time PCR assays for detection of fish predation at the community level in the San Francisco Estuary-Delta. Mol Ecol Resour 15:278-284. https://doi.org/10.1111/1755-0998. 12305

Britton JR, Davies GD, Brazier M (2009) Eradication of the invasive Pseudorasbora parva results in increased growth and production of native fishes. Ecol Freshw Fish 18:8-14. https://doi.org/10.1111/j.1600-0633.2008.00334.x

Burns Paiute Tribe (2018) Resolution 2018-09: "Upper malheur river bull trout conservation policy." Approved by a quorum vote of the Burns Paiute Tribal Council on March 14, 2018

Civade R, Dejean T, Valentini A, Roset N, Raymond J-C, Bonin A et al (2016) Spatial representativeness of environmental DNA metabarcoding signal for fish biodiversity assessment in a natural freshwater system. PLoS ONE 11(6):e0157366. https://doi.org/10.1371/journal.pone. 0157366

DeHaan PW, Schwabe LT, Ardren WR (2010) Spatial patterns of hybridization between bull trout, Salvelinus confluentus, and brook trout, Salvelinus fontinalis in an Oregon stream network. Conserv Genet 11:935-949. https://doi.org/10. 1007/s10592-009-9937-6

Deiner K, Fronhofer EA, Mächler E et al (2016) Environmental DNA reveals that rivers are conveyer belts of biodiversity information. Nat Commun 7:12544. https://doi.org/10. 1038/ncomms 12544

Evans NT, Shirey PD, Wieringa JG et al (2017) Comparative cost and effort of fish distribution detection via environmental DNA analysis and electrofishing. Fisheries 42:90-99. https://doi.org/10.1080/03632415.2017. 1276329

Gozlan RE (2008) Introduction of non-native freshwater fish: is it all bad? Fish Fish 9:106-115. https://doi.org/10.1111/j. 1467-2979.2007.00267.x

Gozlan RE, Britton JR, Cowx I, Copp GH (2010) Current knowledge on non-native freshwater fish introductions. J Fish Biol 76:751-786. https://doi.org/10.1111/j.10958649.2010.02566.X

Gunckel SL (2001) Feeding behavior and diet of native bull trout Salvelinus confluentus and introduced brook trout Salvelinus fontinalis in two eastern oregon streams. Master's thesis, Oregon State University, Corvallis

Hänfling B, Handley LL, Read DS et al (2016) Environmental DNA metabarcoding of lake fish communities reflects long-term data from established survey methods. Mol Ecol 25:3101-3119. https://doi.org/10.1111/mec.13660

Irwin DM, Kocher TD, Wilson AC (1991) Evolution of the cytochrome b gene of mammals. J Mol Evol 32:128-144. https://doi.org/10.1007/BF02515385

Jane SF, Wilcox TM, McKelvey KS et al (2015) Distance, flow and PCR inhibition: eDNA dynamics in two headwater streams. Mol Ecol Resour 15:216-227. https://doi.org/10. 1111/1755-0998.12285

Jerde CL, Mahon AR, Chadderton WL, Lodge DM (2011) "Sight-unseen" detection of rare aquatic species using environmental DNA. Conserv Lett 4:150-157. https://doi. org/10.1111/j.1755-263X.2010.00158.X
Kamorof C, Goldberg C (2018) An issue of life or death: using eDNA to detect viable individuals in wilderness restoration. Freshw Sci 37(3):685-696. https://doi.org/10.1086/ 699203

Kocher TD, Thomas WK, Meyer A et al (1989) Dynamics of mitochondrial DNA evolution in animals: amplification and sequencing with conserved primers. Proc Natl Acad Sci 86:6196-6200

Laramie MB, Pilliod DS, Goldberg CS (2015) Characterizing the distribution of an endangered salmonid using environmental DNA analysis. Biol Conserv 183:29-37. https:// doi.org/10.1016/j.biocon.2014.11.025

McDowall RM (2003) Impacts of introduced salmonids on native Galaxiids in New Zealand upland streams: a new look at an old problem. Trans Am Fish Soc 132:229-238. https://doi.org/10.1577/1548-8659(2003)132\%3c0229: IOISON\%3e2.0.CO;2

Pimentel D, Zuniga R, Morrison D (2005) Update on the environmental and economic costs associated with alien-invasive species in the United States. Ecol Econ 52:273-288. https://doi.org/10.1016/j.ecolecon.2004.10.002

Pringle RM (2005) The Nile Perch in Lake Victoria: local responses and adaptations. Africa 75:510-538. https://doi. org/10.3366/afr.2005.75.4.510

Rees HC, Maddison BC, Middleditch DJ et al (2014) REVIEW: the detection of aquatic animal species using environmental DNA - a review of eDNA as a survey tool in ecology. J Appl Ecol 51:1450-1459. https://doi.org/10. 1111/1365-2664.12306

Rosgen DL (1994) A classification of natural rivers. Catena 22:169-199

Roussel J-M, Paillisson J-M, Tréguier A, Petit E (2015) The downside of eDNA as a survey tool in water bodies. J Appl Ecol 52:823-826. https://doi.org/10.1111/1365-2664. 12428

Teletchea F (2009) Molecular identification methods of fish species: reassessment and possible applications. Rev Fish Biol Fish 19:265. https://doi.org/10.1007/s11160-0099107-4

Thomsen PF, Kielgast J, Iversen LL et al (2011) Monitoring endangered freshwater biodiversity using environmental DNA. Mol Ecol 21:2565-2573. https://doi.org/10.1111/j. 1365-294X.2011.05418.x

US Fish and Wildlife Service (2002) Chapter 14, Malheur Recovery Unit, Oregon, 71 p. In: US Fish and Wildlife Service. Bull Trout (Salvelinus confluentus) Draft Recovery Plan, Portland

US Fish and Wildlife Service (2015) Recovery plan for the coterminous United States Population of Bull Trout (Salvelinus confluentus), Portland

Wilcox TM, McKelvey KS, Young MK et al (2016) Understanding environmental DNA detection probabilities: a case study using a stream-dwelling char Salvelinus fontinalis. Biol Conserv 194:209-216. https://doi.org/10.1016/ j.biocon.2015.12.023

Publisher's Note Springer Nature remains neutral with regard to jurisdictional claims in published maps and institutional affiliations. 